\title{
The Cognitive Paradigm of Psychological Science and the Conceptualization of Giftedness*
}

\author{
Marina Ivleva \\ Faculty of Humanities and Social Sciences \\ Department of Social Philosophy \\ Peoples' Friendship University of Russia (RUDN \\ University) \\ 6 Miklukho-Maklaya Street, Moscow, 117198, Russian \\ Federation \\ E-mail: marinanonna@yandex.ru
}

\author{
Mikhail Oseledchik \\ Department of Philosophy and Social Sciences \\ High School of Printing and Media Industry \\ Moscow Polytechnic University \\ 38 Bolshaya Semenovskaya Street, Moscow, 107023, \\ Russian Federation \\ E-mail: balu13@yandex.ru
}

\begin{abstract}
This article presents one of the possible reasons for the absence of a unified theory of giftedness. The state of the Psychology-accumulated knowledge of giftedness is assessed through the spectacle of the general methodology of the science. The thesis being defended lies in the fact that as its paradigm Psychology uses the already-present, external paradigm, which is of a non-specific, social and cultural origin. And the confirmation of this thesis is the existence of the concept of giftedness.
\end{abstract}

Keywords-giftedness; psychological concept of giftedness; conceptualization; cognitive paradigm; extraparadigmality; crisis of science; metatheory

\section{INTRODUCTION}

The problem of the individual natural advantages of some people over other is one of the oldest in the history of human thought. In various periods of public consciousness or social mind, this problem was understood to have different sounding, filled with new senses and found different solutions. Today, the interpretation and assessment of the history of the steady development and accumulation of such solutions and interpretations require the corresponding cultural and historical contexts to be taken into consideration. From our point of view, the key to understanding and correct assessment of the scientific approaches to this problem in various fields of knowledge lies in learning their cultural and pragmatic roots.

*This paper was financially supported by the Ministry of Education and Science of the Russian Federation on the program to improve the competitiveness of Peoples' Friendship University (RUDN University) among the world's leading research and education centers in the 20162020. (The Agreement number 02.A03.21.0008).

The distinctive feature of the current status of various fields of culture, arts, social studies, philosophy is the position where the diversity of the theoretical and methodological backgrounds and prerequisites underlying the scientific theories or concepts, as well as the leveling of the accumulated facts or their irreducibility to the hierarchic system of the objective reality levels, leads to that the concepts related by their content and envisioned in such diversified areas of knowledge often can neither be brought together, nor fit into a unified theory.

This article attempts to analyze one of the reasons for such state of things by the example of the genesis of the psychological concept of giftedness.

\section{DIFFERENT WAYS OF THE CONCEPTUALIZATION OF GIFTEDNESS AS THE THEORETICAL CONSTRUCTS}

The process of formation and development of the psychological concept of giftedness goes back to such areas of social mind as religion, arts, philosophy, and its evolution can be retraced at the everyday thinking level [1]. Long after, this concept started its self-development within the framework of Psychology as an independent science. And this is due to the fact that in the genetic sense, the concept of giftedness is not a specific psychological concept. This is evidenced by the existence of the analogue of such concept in the ordinary consciousness, while there is a corresponding concept in natural language. We proceed from the fact of the objective existence of giftedness as, first, a social and cultural (not only psychological) phenomenon. The reconstruction of the word-formation composition of such word as 'gifted' and its semantics points to that this word means the availability of some inherited, but not formed, exclusive, special qualities which a person has got as a 'gift' from external forces. In the Explanatory Dictionary by $\mathrm{S}$. Ozhegov, such word as 'gifted' serves as a synonym for 'talented' [2, p. 380], and 'talented' - as 'would-be', 'one who has (a lot) on the ball', etc. [2, p. 684]. Talent, in its turn, is understood as 'outstanding inherited qualities', 'naturegiven distinctive features', etc. [2, p. 684]. In other words, giftedness is like those inherited advantages, which will show themselves inevitably in a more successful human activity and, as a result, will be expressed in the obvious social advantages.

The mutual scientists' understanding can be observed in admission of the fact of the giftedness connection with 
natural abilities. Irrespective of the internal structure of giftedness and its ontological status (or a real phenomenon, or ability), it serves as the system of the individual inherited qualities. However, if giftedness is inherited, this raises questions about its dependence on the cultural and historical conditions of the times, in which such individual has had to live. And a reasonable question then is: why did the concept of giftedness become the subject of psychological reflection only in XX century?

This fact of the history of science finds no explanation, if giftedness is considered as a purely psychic phenomenon. If, however giftedness is considered as the theoretical constructs, the questions of the conditions, under which the Psychological Science envisions such theoretical constructs, the philosophical (ontological, epistemological, anthropological, axiological) and empiric prerequisites, which, at that, it is based on - are of quite a reasonable nature.

Each of the ways of the conceptualization of giftedness among which the philosophical, the religious and ethnic, the empiric, the special (through the spectacle of the certain social sciences), the functional and the integral (within the framework of scientific psychology) ones can be singled out, has its own historical profile, and, at the same time, we may talk of their mutual influence, the result of which is the exchange of the sense-bearing elements between the various areas of human knowledge. These processes result in the formation of the concept of giftedness.

\section{The EPISTEMOLOGICAL StATUS OF THE MODERN PSYCHOLOGY}

In the same way that the modern Psychology does not only have a unified approach to the giftedness definition, but all the existing approaches are based on the essentially different ontological grounds, the pre-Newton physics "from the high antiquity to the late XVII century, there was no period, for which any sole, generally-accepted point of view of the nature of light could be typical" [3, p. 28]. The complete knowledge of the pre-Newton physics of the nature of light was represented by "a plenty of the opposing schools, most of which entertained one or other variety of the Epicurean, the Aristotle or the Plato theory. One group considered the light as the particles emitted by material bodies; to the other one the light was a modification of the environment, which was between the body and the eye; the third group explained the light in the terms of the environment interaction with the radiation of eyes themselves. Apart from these, there were other options and combinations of such explanations" [3, pp. 28-29]

The reason for such concept consisted in that the theories of light began to be formed in physics at its pre-paradigm stage of development, preceding the 'normal' (according to the terms by T. Kuhn) science state. By 'normal science' $\mathrm{T}$. Kuhn meant 'a research that is based solidly on one or several scientific breakthroughs of the past - the breakthroughs which for some period are recognized by a certain scientific community as the basis for its further practical activity" [3, p. 24]. At that, such breakthroughs are envisioned by science itself, but not taken from the outside. T. Kuhn considers Physics as the benchmark for such science.

According to the first definition by T. Kuhn, paradigms are understood as "the widely-considered breakthroughs which for a certain period provides the academic community with a model of setting problems and their solutions" $[3, \mathrm{p}$. 7]. So, a normal science is a science which has envisioned its own paradigm.

As for the social and liberal sciences, the situation here is kind of different. Thus, T. Kuhn states that having spent a year "in a society consisted mostly of the experts in social sciences" [3, p. 6], he "was amazed at the number and degree of the open disputes between sociologists as for the appropriateness of setting some or other scientific problems and the methods of their solution" $[3$, p. 6]. And then he recognizes that "the research practice in astronomy, physics, chemistry or biology is used to give no rise to dispute the principles of such sciences themselves, whilst you can find this all too often among psychologists or sociologists" [3, p. $6]$. These were the differences discovered by T. Kuhn and the search for their sources which allowed for formulating and introducing the concept of 'paradigm', as well as for talking about the 'pre-paradigm', 'paradigm' and 'postparadigm' periods in the science advancement. It is obvious that we are talking about strictly the 'normal' sciences, i.e., those which just for their history have managed to form their own paradigm. Unfortunately, the modern Psychology is outside such sciences: it does not have a unified paradigm yet which is perceived by psychologists themselves as the permanent science crisis symptom. The absence of a unified paradigm is coming out with various schools in "different figures of authority", "different systems of education and economic existence in society, the disjoint communication circles" [4].

The natural consequence of such state of things is a plenty of the alternative explanatory models, the alternative methods of studying the same phenomena, the absence of the unified rules, regulations and algorithms of the knowledge construction and verification. F. Vasilyuk writes about a 'schism' between the research and the practical Psychology [4]. Psychologists also find the crisis symptoms in the permanent competition with the parascience, the massive penetration of the non-specific and theoretically unshapen knowledge.

As for the psychological scientific schools themselves, they not so much compete as ignore each other - the data obtained within the framework of different schools is sometimes inconsistent and incompatible.

Based on these facts, psychologists are talking about the absence of any measurable progress in the Psychological Science development [5].

In the 1970s, many representatives of the Psychological Science (let us remark here that not without the impact of the T. Kuhn concept) were reliant on the appearance of a versatile psychological metatheory, which, when accepted by all psychologists, would play the role of a paradigm towards 
the Psychological Science (within the meaning of T. Kuhn), and which will at last allow for bringing an end to the methodological eclecticism and turn the Psychological Science into a cohesive or an articulate system of scientific knowledge. The most prospective candidates for the role of such metatheory seemed to be the causal attribution theory and the fair exchange theory. However, those expectations were fallen short since in the late XX century the American social psychology was at a low ebb, mostly stipulated by the fact that they were traditionally applying (or, at least, were aiming to apply) the naturalistic criterion of scientific character, whilst natural sciences themselves within the specified time started being subject to the radical rethinking [6]. The new standards for the scientific cognition taken shape in the papers by T. Kuhn, I. Lakatos, P. Feyerabend, W. Sellars, S. Toulmin, M. Polanyi have ousted the positivist myth of naturalistic knowledge [7].

Under such conditions, those psychologists trying to understand the reasons for the permanent 'crisis' of their science were naturally tempted to consider the problem to the extent of a categorical apparatus developed by T. Kuhn for the analysis of natural (at that, 'normal') sciences. Here the following three positions come out, defining the epistemological status of Psychology in different ways.

According to the first position based on a characteristic given to Psychology by T. Kuhn himself, this science is a pre-paradigm area of knowledge, i.e., no paradigm has formed in it yet.

According to the second position popular among psychologists, Psychology is a multi-paradigm science that contains several paradigms represented by the constitutive psychological theories such as behaviorism, cognitivism and psychoanalysis, or in other version: the positivist and the humanistic paradigms.

According to the third position, the concept by T. Kuhn arisen as a result of generalizing the history of natural sciences is in no way applicable to Psychology, which is neither the multi-paradigm, nor pre-paradigm, but the out-ofparadigm area of knowledge [8].

We believe that, based on the above mentioned assessments by T. Kuhn, the most appropriate concept to apply to Psychology is the concept of extraparadigmality, i.e., the existence not just under conditions of the absence of its own unified scientific paradigm (to which the characteristics of the science as the pre-paradigm or out-of-paradigm area of knowledge would correspond), but of the use of external paradigms, i.e., the ones formed outside such science, in other areas of knowledge, and even wider - spiritual life.

To make it clear now - such approach assumes a wider interpretation of the concept of 'paradigm' than in T. Kuhn. However, as it is shown below, there are grounds for that.

First, T. Kuhn himself, describing the confrontation between the 'schools and nurseries' of the pre-Newton physics which entertained "one or other variety of the Epicurean, the Aristotle or the Plato theory", reflects the fact of support of these scientific schools by various philosophical (ontological, epistemological, anthropological, axiological) grounds.

Second, it is recognized that T. Kuhn, within the framework of his theory, uses the term 'paradigm' in a special meaning - narrower than the common meaning of this term, in fact, speaking only of a cognitive paradigm of a certain type of science at a certain stage of its development.

\section{MODIFICATION OF THE PARADIGM DEFINITION}

In its original meaning the word 'paradigm' means 'master sample' in Greek. Modern scholarship regards paradigm as a combination of plans of action, regulations and standards adopted in a certain community towards a certain activity (the education paradigms [9, p. 421], the programming paradigms, the cultural and the linguistic paradigms). Such combination is based on one or another system of representations. When V. Lefebvre writes about "the traditional ways of breakdown which serve as an embodied 'standard' for human activity, like a kind of benchmark, which we, roughly speaking, put onto a real object, like a stencil plate, and so mark out the certain elements in it, required for solving the problems of a certain science" [10, p. 96], then he means a paradigm in the meaning above as a paradigm of a certain area of human activity and a corresponding academic discipline. "For example, - V. Lefebvre continues, - as a result of the centuries-long medical practice, the human body appears to be a system of organs: brain, kidneys, liver, etc. From a young age, we learn this breakdown and we can hardly assume that if for some reasons medical practice formed otherwise, the breakdown of human body into the canonical elements should be different, i.e., the human body should consist of different organs" [10, p. 96].

The concept of paradigm in its generally accepted meaning assumes the following two essential sense-bearing or conceptual moments: first, the forcing, normalizing nature of a paradigm; second, its relatively persistent nature, link to a tradition. Both moments are present in the T. Kuhn concept of scientific paradigm. The first moment comes out in that the science in its evolutionary development cannot go beyond the paradigm shared by scientists; the second - in that the change in a paradigm means the scientific revolution.

The specificity of using the term 'paradigm' by T. Kuhn is in that he limits the area of use of this term to: first, only the research activity in the realm of science; second, only those sciences which produce their paradigms by themselves and only at such stage of development of those sciences, where a paradigm has at least been just once envisioned by science. That is why this term, if used in a strict correspondence with the definition by T. Kuhn, becomes inappropriate for describing many phenomena and facts of the science advancement, and first of all - social sciences, one of which is Psychology.

At the same time, there is no reason why we should not use the concept of 'paradigm' which has a centuries-long history in its general meaning, concretizing such meaning in respect to the object of our research. So, we will speak of the cognitive paradigm as a set of standards for setting scientific 
problems and their solution, based on the representation and belief system shared by a certain scientific community or, at least, by its essential part. At that, the scientific community will be understood as not the whole multitude of the representatives of one science (for example, Psychology), but a real community, i.e., those scientists who maintain the scientific communication with each other. There is no reason why one academic discipline should not be represented by several academic communities. If at that such communities are not united by their common cognitive paradigm, this is an exhaustive explanation for the absence of any scientific communication between them.

Let us remark here that the differences of our concept of paradigm from the T. Kuhn's one amount to the following three key aspects.

Aspect One: the paradigm generality. According to the T. Kuhn's definition, a paradigm is single for one science, it must be shared by all its representatives, otherwise - the paradigms change. In our definition, generality is not a required sign of cognitive paradigm.

Aspect Two: the versatility of applicability of the concept of 'paradigm'. According to the T. Kuhn's definition, this concept is not versatile since it is applicable only to a certain type of sciences - the 'normal' sciences. Our definition allows for speaking of a paradigm in respect to any science.

Aspect Three: the paradigm origin. According to the $\mathrm{T}$. Kuhn's definition, science chooses its own paradigm by itself. As a matter of fact, a paradigm, according to T. Kuhn, consists of scientific achievements, i.e., the scientific results recognized by all its representatives. Our definition allows for studying the paradigms of a non-specific, external origin.

The result of that is, in particular, a potential existence of the paradigms common to two or several sciences and even not only sciences, but other forms of knowledge, areas of social activity. Thus, we may talk of a paradigm common to a few liberal sciences (for example, Psychology, Musicology, Theory and History of Literature, etc.), Arts (Music, Fiction) and Philosophy of a particular direction.

Generally, the proposed paradigm definition is closer to the general meaning of this term than the concept introduced by T. Kuhn.

Having armed with the modified paradigm definition, now we can revert to the baseline of the proposed concept of Psychology as an extraparadigm discipline with good reason. The thesis being defended lies in the fact that as its paradigm Psychology uses the already-present, external paradigm, which is of a non-specific, social and cultural origin. And the best confirmation of this thesis is the concept of giftedness. The reason for the diversity of approaches to studying giftedness in Psychology not so much lies in the versatility of a phenomenon under analysis as in differentiating the cognitive attitudes of researchers, the ways of their thinking, based on the differences between the philosophical grounds.

\section{CONCLUSION}

As it has just been shown in this article and our works ([11], [12], [13]), long before the psychological concept of giftedness started its self-development to the extent of Psychology as a formed science, it had already existed in other social mind areas - first, in Arts, Philosophy, Religion, evolved at the everyday thinking level, sometimes becoming the worldview element $[14,15]$. The process of genesis and development of this concept started long before the time where Psychology had differentiated itself as an independent science characterized by its own subject and specific research methods. After all, in the genetic sense, the concept of giftedness is not a specific psychological concept. The analogue of such concept exists in the ordinary consciousness and is reflected in natural language.

We proceed from the fact of the objective existence of giftedness as, first, a social and cultural (not only psychological) phenomenon. The reconstruction of the wordformation composition of such word as 'gifted' and its semantics points to that this word means the availability of some inherited, but not formed, exclusive, special qualities which a person has got as a 'gift' from external forces.

This is to a large extent connected with the variation of the giftedness conceptualization ways themselves among which the philosophical, the religious and ethnic, the empiric, the special (through the spectacle of the certain social sciences, including Psychology), the functional and the integral (within the framework of scientific psychology) ones can be singled out.

Each of these ways has its own historical profile, and, at the same time, we may talk of their mutual interweaving, mutual influence, the result of which is the exchange of the sense-bearing elements between the various areas of human knowledge. These processes result in the formation of the concept of giftedness.

\section{REFERENCES}

[1] Ivleva M., Bagramiants N., Ivlev V., Oseledchik M. Methodological Principles of the Study of the Philosophical Foundations of Psychological Conceptions of Giftedness//Proceedings of the 2016 3rd International Conference on Education, Language, Art and Intercultural Communication (ICELAIC 2016). Advances in Social Science, Education and Humanities Research. Paris: Atlantis Press, 2017. Volume 40. P.48-52.

[2] Ozhegov S. I. Explanatory dictionary of the Russian language. M.: Russian language, 1986. $-736 \mathrm{p}$.

[3] Kuhn T. S. The Structure of scientific revolutions / Ed. from English. I. E. Naletova. - M.: Progress, 1975. (Series: Logic and methodology of science).

[4] Vasilyuk F. E. Methodological sense of psychological schisis. Questions of psychology, 1996, No. 6, pp. 25-40.

[5] Jurewicz A. V. "Ontological circle" and structure of psychological knowledge. Psychological journal, 1992, vol. 13, No. 1, pp. 6-14.

[6] Stepin V. S. From classical to postnonclassical science (the change of basis and value orientations). Value aspects for the development of science / ed. by V. J. Kelly. M.: Nauka, 1990. - S. 152-166.

[7] Yurevich A. V., Tsapenko I. P. Functional crisis in science. Questions of philosophy, 1998, No. 1, pp. 17-29. 
[8] Rybakov V. A., Pokryshkin A. L.. does the psychology and natural science paradigm? - Tomsk: "Glider", 2005.

[9] Rapatsevich E. S. Pedagogy: Large modern encyclopedia, Minsk, "Modern word", 2005.

[10] Vladimir A. Lefebvre, The Reflection, M.: "Kogito-Center", 2003.

[11] Ivleva M. L. the Philosophical bases of psychological conceptions of giftedness. M.: MGTU "MAMI", 2011.

[12] Baghramyants M. L. Psychology of giftedness: theory, experiment, practice. M.: MALY, 2003.

[13] Bagramyants M. L. The psychological concepts of giftedness: a theoretical and historical study. M.: MGTU "MAMI", 2008.

[14] Chistyakova O.V. Russian Religious Philosophy as the Basis for State Identity // Journal of Eurasian Research. 2003. Volume 2. № 1. ISSN 1538-0378. P. 13-17.

[15] Chistyakova O.V. Postmodernism, Christian Patristics, and Values of Peace in the Modern Cultures In the Context of Educational Process // «Proceedings of the 2016 International Conference on Arts, Design, and Contemporary Education. Volume 64 (ICADCE 2016) Advances in Social Science, Education and Humanities Research». Atlantis Press. - Paris. France. 2016. ISSN 2352-5398. P. 996-1000 